\title{
APRENDIZAGENS DA TERRA NAS NARRATIVAS DAS \\ MULHERES DO QUILOMBO MATA CAVALO
}

\author{
EARTH LEARNING IN THE NARRATIVES OF FEMALE \\ OF QUILOMBO MATA CAVALO
}

\section{APRENDIZAJES DE LA TIERRA EN LAS NARRATIVAS DE MUJERES DE LO KILOMBO MATA CAVALO}

\author{
Junia Auxiliadora Santana ${ }^{1}$ \\ Grupo Pesquisador em Educação Ambiental, Comunicação e Arte (GPEA). \\ Universidade Federal de Mato Grosso, Cuiabá, MT \\ Orcid: https://orcid.org/0000-0003-0718-5047 \\ E-mail: juniasantana@hotmail.com \\ Regina Aparecida Silva ${ }^{2}$ \\ Programa de Pós-Graduação em Educação (PPGE/UFMT) e Grupo Pesquisador \\ em Educação Ambiental, Comunicação e Arte (GPEA), Rondonópolis, MT \\ Orcid: https://orcid.org/0000-0002-2207-8437 \\ E-mail: rasbio@gmail.com \\ Giseli Dalla Nora ${ }^{3}$ \\ Docente da Universidade Federal de Mato Grosso. Grupo Pesquisador em \\ Educação Ambiental, Comunicação e Arte (GPEA), Cuiabá, MT \\ Orcid: https://orcid.org/0000-0002-8890-7832 \\ E-mail: giseli.nora@gmail.com
}

Resumo: Esta pesquisa foi desenvolvida na Comunidade Quilombola de Mata Cavalo, município de Nossa Senhora do Livramento, estado de Mato Grosso. Como participantes de pesquisa, temos algumas representantes femininas do Quilombo Mata Cavalo. O objetivo foi conhecer as narrativas de aprendizagem de dez mulheres comprometidas com as lutas pelas terras quilombolas, discutindo a terra e o cuidado ambiental. Observamos se estas lutas incluem o cuidado ambiental, e por serem mulheres, como aprendem a conciliar a maternidade com as travessias cotidianas. Para tal, utilizamos como metodologia a pesquisa participante, realizando entrevistas e observação com anotações em caderno de campo, gravação de áudio, vídeo e fotografias. Registramos que as principais táticas de resistência estão no reconhecimento do coletivo, na criação de associações e nos processos educativos

\footnotetext{
1 Mestre pela Universidade Federal de Mato Grosso (UFMT).

2 Profa. Dra. da Universidade Federal de Mato Grosso (UFMT). Possui Pós-Doutorado em Educação pela mesma instituição.

3 Doutora em Educação pela Universidade Federal de Mato Grosso (UFMT).
} 
vivenciados nas mobilizações, manifestações, campanhas e ações coletivas.

Palavras-chave: Mulheres. Resistências. Comunidade Quilombola.

Abstract: This research was developed in the Quilombola Community of Mata Cavalo, municipality of Nossa Senhora do Livramento, state of Mato Grosso. We have, as research participants, some female representatives of Quilombo Mata Cavalo. The objective was to learn about the learning narratives of ten women committed to the struggles for quilombola lands, discussing land and environmental care. We observed whether these struggles include environmental care and, being women, how they learn to reconcile motherhood with daily crossings. To this end, we used participatory research as a methodology, conducting interviews, and observation with notes in a field notebook, audio recording, video and photographs. We note that the main resistance tactics are in the recognition of the collective, in the creation of associations and in the educational processes experienced in the mobilizations, demonstrations, campaigns and collective actions.

Keywords: Women. Resistances. Quilombola community.

Resumen: Esta investigación se desarrolló en la Comunidad Quilombola de Mata Cavalo, municipio de Nossa Senhora do Livramento, estado de Mato Grosso. Tenemos, como participantes de la investigación, algunas mujeres representantes del Quilombo Mata Cavalo. El objetivo fue conocer las narrativas de aprendizaje de diez mujeres comprometidas con las luchas por las tierras quilombolas, discutiendo la tierra y el cuidado del medio ambiente. Observamos si estas luchas incluyen el cuidado del medio ambiente y, siendo mujeres, cómo aprenden a conciliar la maternidad con los cruces diarios. Para ello, se utilizó como metodología la investigación participativa, la realización de entrevistas y la observación con apuntes en un cuaderno de campo, grabación de audio, video y fotografías. Observamos que las principales tácticas de resistencia están en el reconocimiento del colectivo, en la creación de asociaciones y en los procesos educativos vividos en las movilizaciones, manifestaciones, campañas y acciones colectivas.

Palabras Clave: Mujeres. Resistencias. Comunidad Quilombola.

Data de recebimento: $26 / 10 / 2020$

Data de aprovação: 20/12/2020

\section{1 - INTRODUÇÃO}

Esta pesquisa tem como objetivo compreender as trajetórias de vida e saberes da terra e cuidado ambiental de mulheres negras do Quilombo Mata Cavalo ${ }^{4}$. Buscamos conhecer as narrativas de aprendizagens de algumas mulheres que estão comprometidas com as lutas pelas terras quilombolas, sobre os obstáculos existentes e táticas de resistência, se

4 Escrita adotada no trabalho para o termo "Mata Cavalo" a partir dos registros oficiais constantes nas organizações e órgãos federais como: Instituto Nacional de Colonização e Reforma Agrária (INCRA), Fundação Cultural Palmares (FCP). 
estas lutas incluem o cuidado ambiental, e por serem mulheres, como aprendem a conciliar a maternidade com as travessias cotidianas.

Para isso, buscamos identificar algumas mulheres matacavalenses aguerridas da comunidade quilombola. Guerreiras que, além de cuidadoras do lar e dos filhos, exercem papel de empoderamento dentro da comunidade, cujos cotidianos sempre foram marcados por lutas e enfrentamentos em situações adversas, tais como: falta de infraestrutura básica, falta de moradia adequada, falta de escola para os filhos, conflitos com os fazendeiros e inúmeros despejos.

Conforme Silva e Sato (2010, p. 09), o Quilombo Mata Cavalo "é uma porção de terra, para além de territórios geográficos, na qual se inscreve em identidades construídas nas vivências históricas que demarcam sua temporalidade". O complexo quilombola Mata Cavalo está localizado no município de Nossa Senhora do Livramento-MT, a cinquenta quilômetros da capital Cuiabá, às margens da rodovia MT 060, que interliga Cuiabá a Poconé. De acordo com o cadastro do Instituto Nacional de Colonização e Reforma Agrária (INCRA), em 1996 viviam cerca de 420 famílias na comunidade, organizadas em seis associações que formam o Complexo Sesmaria Boa Vida Quilombo Mata Cavalo (BARROS, 2007). Hoje, as narrativas em entrevistas relatam mais de 500 famílias vivendo neste território, o cerrado matacavalense (Figura 1). Existem seis associações: Aguaçu, Mata Cavalo de Baixo, Ponte da Estiva, Mutuca, Capim Verde e Mata Cavalo de Cima. Quatro destas são presididas por mulheres, sendo elas: Aguaçu, Mata Cavalo de Baixo, Ponte da Estiva e Mutuca. Diante disso, percebemos a força que as mulheres exercem nestas comunidades, seja com a presença massiva nas associações, no contexto escolar como educadoras, como cuidadoras de seus filhos e no trabalho cotidiano na agricultura.

Figura 1 - Paisagens do Cerrado no Quilombo Mata Cavalo.

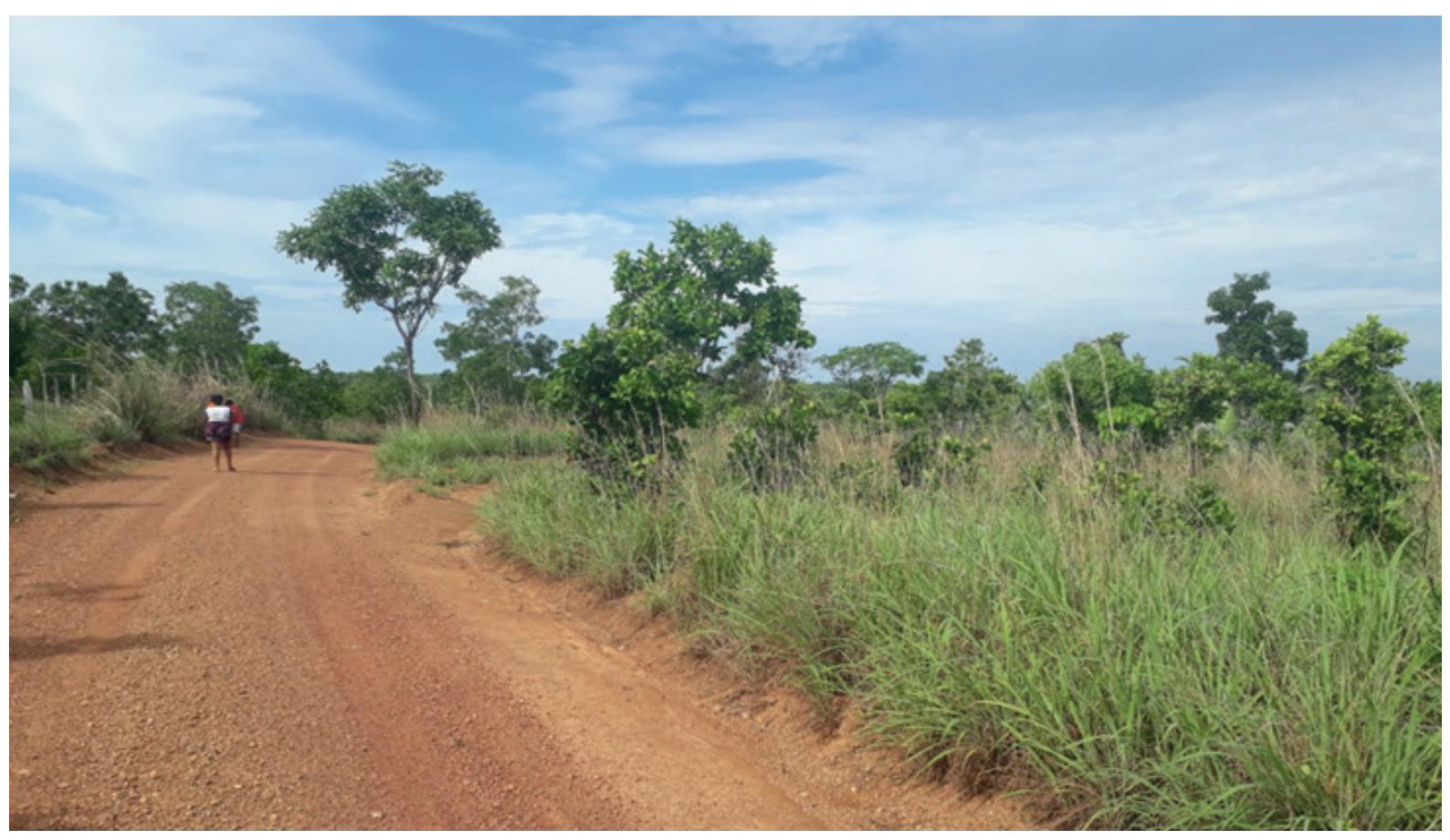

Fonte: Júnia Santana, março de 2018. 


\section{2 - A COMUNIDADE QUILOMBOLA DE MATA CAVALO: LÓCUS DA PESQUISA}

No Brasil, 2.131 comunidades constam no cadastro geral de comunidades remanescentes de quilombos da Fundação Cultural Palmares, localizadas nas mais diversas regiões brasileiras. Em Mato Grosso, segundo dados da Fundação, são 77 comunidades 5 .

Manfrinate e Sato (2012) apontam que Mata Cavalo foi reconhecida pelo Decreto Presidencial de 05 de novembro de 2007, após ter sido elaborado o Relatório Técnico de Identificação e Delimitação (RTID). Muitos avanços podem ser percebidos na comunidade, todavia, ainda se tem muito a conquistar, principalmente, a legalização definitiva das terras.

É necessário contextualizar como se deu o processo histórico da Comunidade Quilombola de Mata Cavalo e como a efetivação de luta e resistência foi se consolidando ao longo do tempo, com base em minha história, como mulher negra e quilombola, nas narrativas das entrevistas, assim como nos diálogos com os quilombolas de Mata Cavalo.

Os quilombolas se originaram de uma linha de parentesco, ou seja, do tronco familiar que está na Sesmaria Boa Vida desde o ano de 1889. Segundo Simione (2008), os primeiros escravos que chegaram à região eram sudaneses de Mina e Nagô, havendo destaque também para os negros banto, oriundos de Benguela, Congo e Angola. Segundo Simione (2008), entre 1804 e 1883, aproximadamente 60\% dos escravizados de Nossa Senhora do Livramento eram "não africanos", ou seja, negros escravizados que nasceram no Brasil. É importante salientar que a Sesmaria Boa Vida - a qual foi concedida no período da descoberta do ouro nas terras de Cuiabá, a partir de 1751, ao bandeirante paulista Santana do Parnaíba, conhecido como José Paes Falcão, quando da instalação da sede da capitania em Cuiabá pelo primeiro capitão-general da capitania de Mato Grosso, Antônio Rolim de Moura - localizava-se em capão de mata cortada por três córregos: Mutuca, Estiva e Mata Cavalo (Figura 2). 
Figura 2 - Paisagens do Cerrado no Quilombo Mata Cavalo

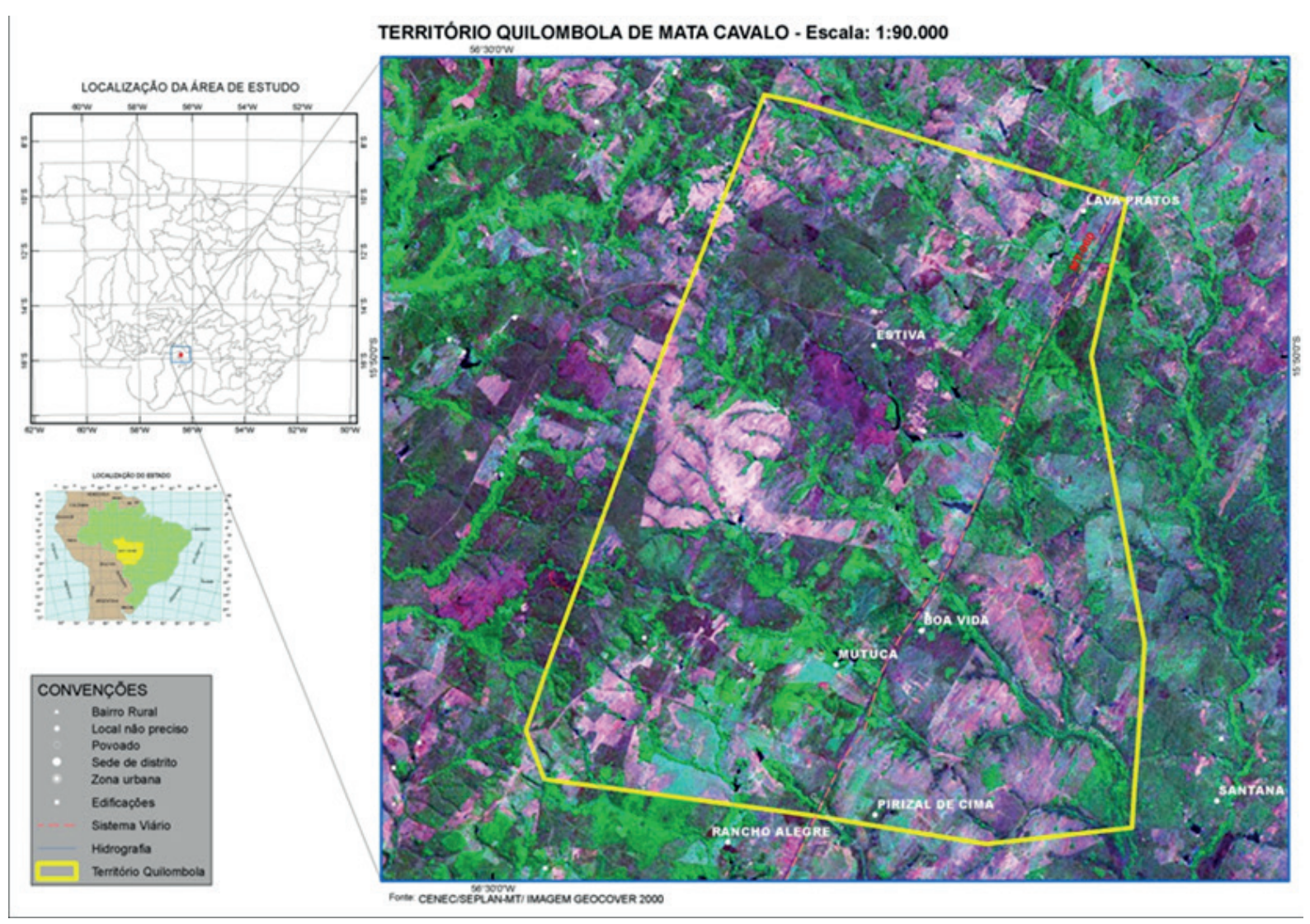

Fonte: Silva, 2010.

Em 1772, Antônio Raiz de Siqueira comprou a Sesmaria Boa Vida do primeiro sesmeiro e posteriormente repassou sua posse judicial ao seu filho Antônio Xavier de Siqueira, após a área ter sido medida e demarcada em 1778. Antônio Xavier de Siqueira faleceu em 1804 e seu inventário aponta para uma divisão da Sesmaria, tendo como divisor natural o córrego Mata Cavalo, separando-as em Boa Vida do Sul, pertencente à família Siqueira Rondon, localizada ao Norte e o outro lado pertencente à família de mesmo nome.

A historiadora Roberta Simione (2008) afirma que das famílias locais, com posse de terra e possuidoras de escravizados, destacavam-se: Almeida Lara, Xavier de Siqueira, Rondon, Campos Maciel, Moura Meirelles e Arruda Silva. E, entre 1848 e 1849, o segundo esposo de Dona Custódia de Arruda e Silva contraiu uma dívida com João José de Siqueira, fazendo com que a Sesmaria Boa Vida e o engenho fossem arrematados em leilão público por Ricardo José Alves Bastos, esposo de Dona Ana Maria de Almeida Lara. Enfim, com o falecimento de Ricardo José Alves Bastos em 1875, o mesmo deixa o testamento em aberto e na presença de cinco testemunhas declara livres todos os escravizados como se de ventre livre nascessem, após a morte de sua esposa Dona Ana da Silva Tavares. Esta, ao falecer em 1889, deixa em testamento a libertação de seus 38 escravos e doa parte das terras que possuía para 
eles, localizada no ribeirão de nome Mata Cavalo - certamente por não possuir herdeiros.

Entretanto, em mais um processo de discriminação e injustiça, os/as quilombolas são forçados a sair de suas terras, por perseguição e imposição dos fazendeiros e dos poderosos da época. Quando? Estavam lá desde 1889 e são forçados a sair em vários momentos durante todo o século XX.

De acordo com Sato et al. (2010), o movimento pela retomada das terras ganha força no ano de 1996, momento em que os/as quilombolas se juntaram e começaram a lutar por suas terras - e uma das pioneiras nesta luta foi a saudosa Dona Tereza Conceição Arruda e sua neta, a professora Gonçalina Eva de Almeida Santana, dentre outras quilombolas que, direta e indiretamente, sempre estiveram resistindo a toda forma de opressão.

As mulheres estiveram à frente das lutas, pois, para algumas delas, ser mulher é estar em ação, enfrentando empreitadas na batalha do dia a dia, com múltiplos papéis e funções, como: mulher, mãe, dona de casa, profissional etc.

Segundo Dealdina e Pinto (2017), o Decreto $N^{\circ} 4887 / 03$, que regulamenta o procedimento para identificação, reconhecimento, delimitação, demarcação e titulação das terras quilombolas, é a mais bela declaração de reconhecimento de um povo historicamente excluído. Com o objetivo de disciplinar o falso cenário democrático, lembrando a dívida histórica do Brasil para com o povo negro, neste caso os quilombolas, o decreto se traduz em reconhecimento de mulheres e homens que resistem nestes espaços de ancestralidade e identidade quilombola.

Gonçalves e Spazziani (2005) relatam que, no Ato das Disposições Constitucionais Transitórias (ADCT), o Art. 68 declara que: "aos remanescentes das comunidades de quilombo que estejam ocupando suas terras, é reconhecida a propriedade definitiva, devendo o Estado emitir os títulos definitivos" (BRASIL, 1988, p.XX). Contudo, percebemos que o sonho da regulamentação do território ainda demanda um olhar daqueles que detêm o poder, pois, os quilombolas lutam incansavelmente para que este sonho se concretize o mais rápido possível.

\section{3 - A METODOLOGIA: PESQUISA PARTICIPANTE}

A metodologia adotada neste trabalho foi a pesquisa participante, pelo fato de ser quilombola e fazer parte desta luta, que vem de gerações. Ansiava por conhecer a vida e as memórias do meu povo, que também são minhas, e que nos fazem participantes de nossa própria história (FREIRE, 1996).

Saliento (ainda) que a participação na qual me incluo soma-se ao fato de ser mulher, negra e professora quilombola, pois, a pesquisa participante, como aporte metodológico neste trabalho, não se finda somente por eu fazer parte do Quilombo Mata Cavalo.

Neste sentido, Brandão (2007, p. 55) afirma que: 
A pesquisa participante é um momento de trabalho de educação popular realizado junto com e a serviço de comunidades, grupos e movimentos sociais, em geral, populares. É do constante diálogo não doutrinário de parte a parte que um consenso sempre dinâmico e modificável deve ir sendo também construído. Uma verdadeira pesquisa participante cria solidariamente, mas nunca impõe partidariamente conhecimentos e valores.

Diante disto, contextualizo a luta na qual estou inserida, por meio da minha caminhada que se materializa com a construção coletiva realizada no ambiente escolar e que se estende na comunidade. E esta interação de lutas e resistências é preconizada no cotidiano, em consonância com a comunidade escolar e a comunidade mais ampla, em que busco contribuir com projetos, como: inserção e manutenção dos professores quilombolas na unidade escolar; elaboração de documentos para a permanência das salas anexas, de modo que haja a manutenção destas salas integradas à escola do quilombo; reivindicação junto à assessoria pedagógica do direito a um ensino diferenciado, o qual consta nas Diretrizes Curriculares para a Educação Escolar Quilombola e que, por muitas vezes, não são cumpridas devido o racismo institucional que nos assola constantemente; além de trabalhos realizados com os estudantes e seus pais/responsáveis, a fim de que se consolide ainda mais a valorização e a identidade cultural matacavalense.

Ainda, como professora quilombola, estou à frente da presidência do Conselho Deliberativo do Conselho Escolar (CDCE) da rede estadual e ao longo destes seis anos busco contribuir na gestão escolar, combatendo, de forma integrada junto com os participantes da comunidade, a discriminação, o preconceito e o racismo institucional dos quais a Escola Estadual Quilombola Tereza Conceição Arruda tem sido vítima ao longo destes últimos anos.

Demonstro minha interação participativa na comunidade escolar matacavalense, enfatizando meu compromisso no fazer pedagógico nas disciplinas de Geografia e História, indo além da sala de aula e daquele ensino que somente decodifica, trazendo uma aprendizagem que valoriza o quilombola para atuar como cidadão, para que possa enfrentar este nosso mundo desigual. Brandão (2007) aponta a importância do compromisso com a transformação na prática da pesquisa participante:

A pesquisa participante deve ser praticada como um ato de compromisso de presença e de participação claro e assumido. E é a possibilidade de transformação de saberes, de sensibilidades e de motivações populares em nome da transformação da sociedade desigual, excludente e regida por princípios e valores do mercado de bens e de capitais, em nome da humanização da vida social, que os conhecimentos de uma pesquisa participante devem ser produzidos, lidos e integrados como uma forma alternativa emancipadora de saber popular (p. 55).

Desta forma, reitero que compactuar com este processo é também dar visibilidade à comunidade da qual faço parte. As marcas da discriminação nos afligem constantemente, sobretudo na atual conjuntura política que estamos vivendo e nas lutas travadas no quilombo. Como professora, busco, junto à comunidade, minimizar esta situação excludente que, mesmo 
nos deixando marcas, nunca fará com que deixemos de lutar. Nesta premissa, comungamos com o pensamento de Freire (1996, p. 79-80), o qual aponta que:

É assim que venho tentando ser professor, assumindo minhas convicções, disponível ao saber, sensível à boniteza da prática educativa, instigado por seus desafios que não lhe permitem burocratizar-se, assumindo minhas limitações, acompanhadas sempre do esforço por superá-las, limitações que não procuro esconder em nome mesmo do respeito que tenho aos educandos.

Todavia, estender este empoderamento para os estudantes, assim como para a comunidade, é poder doar-me ao campo no qual me comprometi com o povo de Mata Cavalo, pelo ato de educar, mas também de aprender, embora com limitações, firma resistência e persistência e faz com que constantemente as superemos.

Diante deste contexto, apresento como foi a trajetória de entrevistas semiestruturadas no Quilombo Mata Cavalo, realizadas de uma maneira integrada, respeitando o tempo e o espaço de cada uma das dez mulheres quilombolas.

As entrevistas iniciaram em março de 2018. Entre idas e vindas, foram exatamente três semanas, percorrendo as casas das participantes e observando detalhadamente o cotidiano delas. Nesta trajetória foi possível observar a luta diária, o raro descanso que acontecia na hora de tomar um guaraná ralado ou de almoçar, porque sempre estavam em alguma atividade. As entrevistas, em determinadas circunstâncias, eram realizadas durante a preparação do almoço, no atendimento do bar, na hora do intervalo da escola, limpando o quintal ou na varanda de suas casas. Foi como muitas delas me receberam, e eu sempre estava disponível para tudo, buscando interferir o mínimo possível na rotina.

As entrevistadas foram escolhidas da seguinte maneira: cinco que estão presidindo as associações existentes no quilombo e cinco que se destacam na luta durante os enfrentamentos por terra e melhores condições de vida. As entrevistas ocorreram de maneira tranquila, porém algumas perguntas tiveram que ser reformuladas para que houvesse maior consistência na pesquisa e, por este fato, o diálogo foi demorado e minucioso.

Durante as entrevistas, é interessante lembrar que, embora as perguntas fossem iguais para todas as mulheres, os relatos de algumas delas trilhavam caminhos e olhares diferenciados, mas com a retomada das perguntas elas voltavam ao foco do diálogo. Foram utilizados caderno de campo, gravador, máquina fotográfica e o roteiro de perguntas. Sempre antes de começar a entrevistá-las, eu apresentava a proposta do trabalho e a importância de tê-las como participantes.

As mulheres entrevistadas gostam muito de conversar e, por eu fazer parte da comunidade, estas conversas se estendiam ainda mais. E foi justamente em um destes diálogos que surgiu a ideia de denominá-las com nome de árvores, frutos e plantas do Cerrado, para assegurar o anonimato exigido nas pesquisas acadêmicas. E a cada casa que eu chegava, eu expunha os nomes das árvores e frutos, perguntando a elas suas preferências e assim se originaram os apelidos das entrevistadas. 
Como mulheres, as guerreiras quilombolas sempre estavam desenvolvendo alguma atividade, seja cuidando dos filhos, de pais idosos, na plantação, atendendo em seus pequenos comércios e também na correria do planejamento escolar.

Com este processo de pesquisa, realizado com as quilombolas que entrevistamos, aprendemos muito, sobretudo no que concerne ao exercício de escutar mais do que falar, conforme bem nos ensina Freire (1996), ao afirmar que:

Se, na verdade, o sonho que nos anima é democrático e solidário, não é falando aos outros, de cima para baixo, sobretudo, como se fôssemos os portadores da verdade a ser transmitida aos demais, que aprendemos a escutar, mas escutando que aprendemos a falar com eles. Somente quem escuta paciente e criticamente o outro, fala com ele, mesmo que, em certas condições, precise de falar a ele (p. 127-128).

Considero que a travessia com estas guerreiras que entrevistei foi de um aprendizado impagável, inestimável, em que pude realizar o exercício do saber escutar. E este processo contribuiu muito para transcrever as respostas, pois, com a minha vivência na comunidade, percebo isto como sendo uns destes processos que nos desafia a pesquisar cada vez mais e que, por fim, vai nos moldando como pesquisadores.

\section{4 - RESULTADOS - TERRA E CUIDADO AMBIENTAL}

A análise se intitula "Terra e Cuidado Ambiental" e tem como foco a relação da comunidade com o ambiente na visão das mulheres entrevistadas. Passa por educação ambiental, identidade coletiva feminina e quilombola, desigualdade de gênero e protagonismo feminino, ocupação do território e desigualdade ambiental, diferenças entre moradores antigos e recentes do quilombo quanto ao cuidado ambiental, e volta à educação ambiental. Observando as reflexões provocadas pelas questões: você sempre morou no quilombo? Como é a relação da comunidade com o ambiente? Você percebe mudança no ambiente?

Buscamos entender como é a relação da comunidade com o ambiente e, diante deste contexto, como estas mulheres entrevistadas consideram que a Educação Ambiental é um processo de aprendizagem permanente, baseado no respeito a todas as formas de vida, em conformidade com o que registraram Leroy e Pacheco (2005, p. 134):

A educação ambiental é uma educação amorosa, educação do cuidado para com a terra e para humanidade: educação para paz, pois a guerra aniquila a vida, e a violência ofende a dignidade da humanidade. Mas a Educação Ambiental, para que chegue lá, que é preciso enfrentar as desigualdades e os que as promovem.

Concordando com a citação acima, falar sobre o cuidado da terra e buscar este ambiente conservado tem sido um desafio no território quilombola, sobretudo pelo fato de a grande quantidade de fazendas com pastagens contribuem para o processo de desmatamento 
e empobrecimento do solo - o que faz com que os plantios realizados de maneira orgânica sofram influência direta da devastação, causando prejuízos para todos do local, aumentando, assim, as mazelas sociais.

As observações, estudos e interpretações das respostas referentes as três primeiras questões do nosso roteiro de entrevista permitiram confirmar que a relação de identidade e pertencimento na comunidade Mata Cavalo indica que a apropriação do território e a luta por este direito se dão por se tratar das terras de seus ancestrais, bem como pelas condições em que ocorreram a colonização e escravidão, em que desde o primórdio trabalharam como escravizados e conquistaram seu pedaço de chão, por meio das lutas e reivindicações de seus direitos.

Neste sentido, Ribeiro, em sua obra Sesmeiros (1998, p. 30), nos diz que "a permanência das representações arcaicas e das formas tradicionais de organização para o trabalho é que permite a existência deste grupo enquanto identidade diferenciada e destacada da sociedade envolvente". Assim, a identidade definida a partir do sentimento de pertencimento ao espaço historicamente construído da Comunidade Quilombola de Mata Cavalo se fez presente desde o início do seu movimento de luta e resistência. A maioria das entrevistadas relatam que sempre moraram no quilombo. Algumas nasceram fora do quilombo, mas logo retornaram para seu território. Isto aconteceu por volta de 1996, de acordo com os relatos, quando houve o Comboio Simão, uma grande ação de resistência e retomadas das terras após a expulsão.

Sato e Passos (2003) destacam que é a partir do reconhecimento do território, identidade e pertencimento que se torna possível perceber e identificar a luta de um povo e a manutenção de sua cultura e vida, pois, segundo a autora e o autor a:

[...] dimensão política da Educação Ambiental, que diz respeito ao entendimento da identidade social e cultural de uma comunidade e a luta por seu território, onde tem suas raízes, seus significados simbólicos, através do manejo de suas práticas com a natureza sendo impossível manter suas tradições sem o local em que vivem (SATO; PASSOS, 2003, p. 25).

A partir de seus estudos e pesquisas, Sato et al. (2018) ratificaram os entendimentos anteriores de Sato e Passos (2003) sobre a importância da Educação Ambiental, para entender a história de luta e resistência de comunidades, como é o caso da nossa pesquisa, ao destacar que:

Para os educadores ambientais, entretanto, o ambiente não é um mero qualificador neutro ou temporariamente necessário à educação, mas o ambiente é um substantivo político que explicita as lutas construídas no campo ecologista. Para os educadores ambientais, a educação que se estabeleceu de forma excludente é hegemônica e há necessidade de termos diversos caminhos alternativos para que a identidade em fluxos (EU) dos sujeitos, em face às relações sociais onde ele vive (OUTRO) seja uma aprendizagem no universo e cosmologia onde estão inscritos (MUNDO) (SATO et al., 2018, p. 46).

Aponta-se ainda, a partir das entrevistas, que um dos marcos mais importantes da comunidade se refere à questão da consciência da identidade coletiva e, principalmente, do feminino, de se reconhecer como mulher negra e quilombola, repassando às demais a 
consciência do que se é, reforçando a construção da sua identidade em meio ao coletivo. Este reconhecer-se sujeito coletivo de direito é uma grande tática de resistência desta comunidade.

Outro ponto importante a ser destacado é o fato de podermos afirmar que a relação da comunidade com o meio que ocupa é demarcada a partir das relações familiares, das associações, das escolas, ou ainda na divisão entre os afazeres da casa e da roça, como também de outros espaços de socialização e de produção da comunidade. Neste sentido, homens e mulheres matacavalenses apresentam diferenças a partir dos espaços ocupados e da respectiva função de cada grupo e gênero. As associações por exemplo representam um espaço de produção e organização social em prol da melhoria da qualidade de vida da população. Por meio das associações, as mulheres quilombolas reproduzem a vida social, educam seus filhos e fortalecem os valores ancestrais. Cabe destacar ainda que por meio das associações esta comunidade tem acesso recursos de editais para fortalecimento de suas ações produtivas. Em Mata Cavalo, por exemplo, a escola da Comunidade Quilombola é onde se centram as lutas - não existe separação com o entorno em que está inserida, como citamos anteriormente.

Percebe-se, pois, que a relação de gênero expressa significados e sentidos, tanto para os homens como para as mulheres, uma vez que dá importância às funções na organização social e política da comunidade Mata Cavalo. Porém, destaca-se que as mulheres matacavalenses ocupam espaços primordiais de manutenção e resistência, impedindo a dispersão da comunidade, uma vez que, além de sempre cuidarem de seus afazeres diários, participam ativamente da organização social e política da comunidade como membros das associações e, na maioria destas, com sua maior representatividade (presidentas).

Nas palavras de Acselrad (2005, p. 43), "a desigualdade ambiental é uma das expressões da desigualdade social que marca a história do nosso país". Os relatos nos apontam que os/as quilombolas têm uma relação de cuidado e respeito com o ambiente de sobrevivência, quando o cuidado e uso consciente se estabelecem para manutenção de todas as vidas.

Quadro 1 - Ipê Amarelo

\begin{tabular}{|c|c|}
\hline $\begin{array}{r}\text { Entăo os mais velhos, eles têm todo um ritual para lidar } \\
\text { com o ambiente, esses que sempre moraram no quilombo; agora } \\
\text { as pessoas, por exemplo, que moravam na cidade, tiveram que se } \\
\text { adaptar e a gente sabe que para você conseguir ficar num lugar, } \\
\text { você precisa inserir nessa cultura um novo modo de viver e geral- } \\
\text { mente na cidade năo se respeita muito essa questăo do ambiente; } \\
\text { encontramos alguns obstáculos nesse quesito, sobretudo, dessas } \\
\text { pessoas que voltaram e năo têm esse cuidado com o ambiente, } \\
\text { diferentemente daqueles que sempre viveram da terra, sempre } \\
\text { estiveram aqui e nunca saíram. Entâo, às vezes, a gente tem } \\
\text { esses conflitos e precisa estar falando, sensibilizando as pessoas } \\
\text { da necessidade de conservar o ambiente, ou seja, respeitar (Ipê } \\
\text { Amarelo, 2018, Mata Cavalo). }\end{array}$ \\
\hline IpêtAmardo
\end{tabular}

Fonte: Elaborado pelas autoras. 
Desde a década de 1990 houve uma intensificação na degradação do córrego. Hoje, o córrego está muito assoreado, com pouca vegetação ciliar e a nascente muito desprotegida. Isto se reflete na diminuição das águas, na qualidade da água e na diminuição dos peixes, o que interfere na vida dos/as quilombolas.

Relatam também sobre a diminuição das áreas de matas e das plantas medicinais. Isto é muito ruim, pois, o uso de plantas medicinais está muito associado à cultura e à vida dos quilombolas.

Outro ponto narrado é sobre as mudanças no clima, aumento da temperatura, diminuição dos índices pluviométricos e excesso de queimadas em períodos de estiagem. Isto tudo acarreta a diminuição da fauna local.

\section{Quadro 2 - Hortelã do Cerrado}

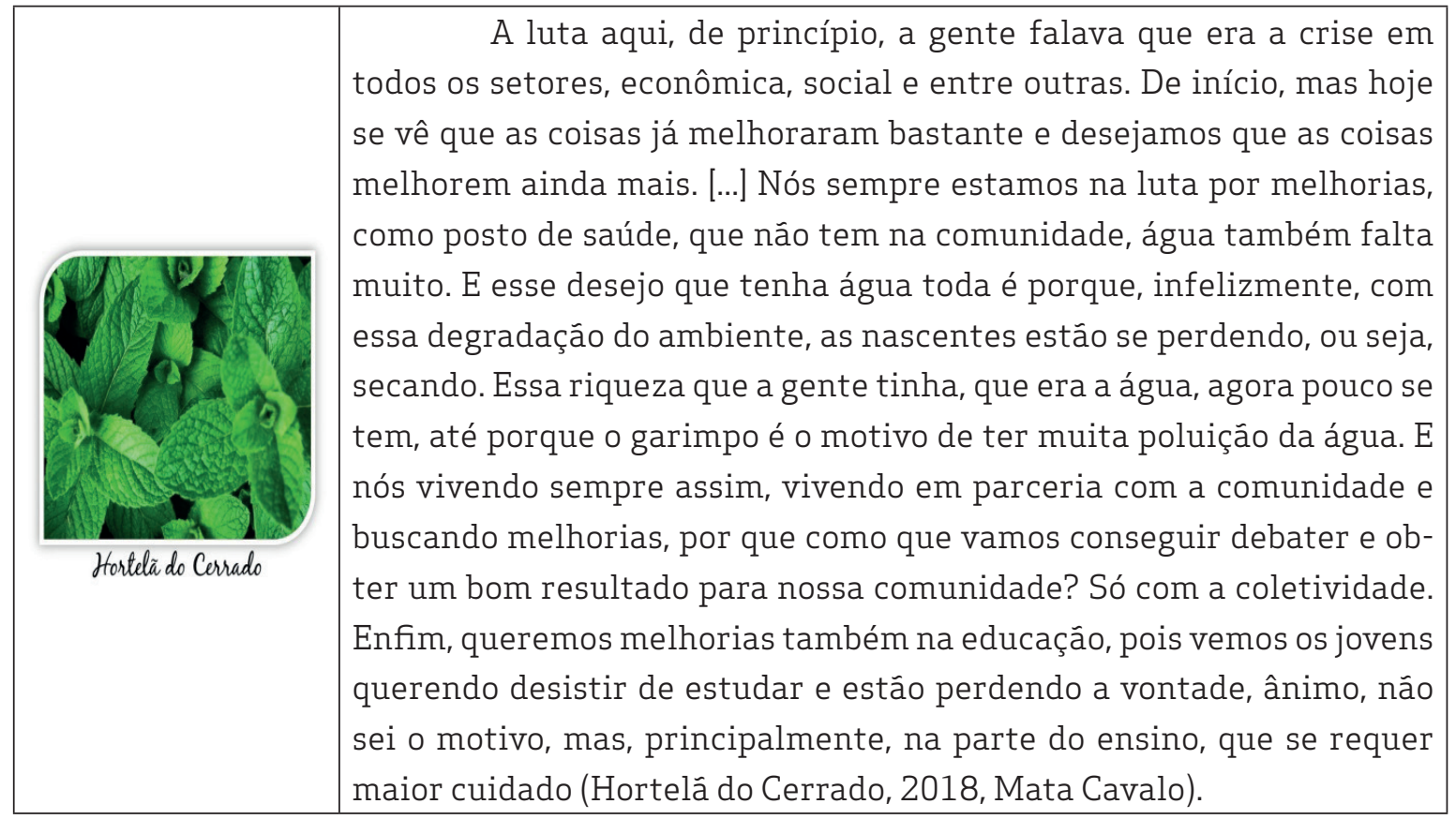

Fonte: Elaborado pelas autoras.

Os relatos apontam a dificuldade de acesso à água, as nascentes secando, as águas superficiais sendo contaminadas, principalmente, pelo garimpo. Um exemplo é um poço artesiano (Figura 3) que tem no entorno da escola que abastece, além da escola, dezenas, talvez centenas, de famílias que buscam água nele. Pensamos: até quando ele dará conta de abastecer tantas pessoas? 
Quadro 3 - Ipê Branco

\begin{tabular}{|c|c|}
$\begin{array}{r}\text { A relaçăo de nós, quilombolas, é toda voltada pela vida por- } \\
\text { que a mulher cuida da vida, tanto é que você pode pegar histórias das } \\
\text { sementes, ela começa a germinar frutos e com as mulheres quilom- } \\
\text { bolas náo é diferente, eu costumo também comparar a nossa relaçáo } \\
\text { com a natureza, com deserto e com as flores, as mulheres săo sempre } \\
\text { as flores e elas nunca văo ser o deserto, porque náo tem o hábito de } \\
\text { devastar tudo que a natureza dá. Entăo, a măe natureza é riquíssima, } \\
\text { ela nos dá muitas coisas e as mulheres, principalmente, da comunidade } \\
\text { quilombola de Mata Cavalo tem essa correlaçáo com a natureza, pois, a } \\
\text { partir do momento que reservamos e tiramos só o que é essencial para } \\
\text { a sobrevivência, năo se maltrata. E nós temos toda essa questấo até no } \\
\text { trabalho da produçăo agroecológica, entăo a mulher quilombola, nesse } \\
\text { contexto, conserva, cuida (Ipê Branco, 2018, Mata Cavalo). }\end{array}$ \\
\hline IpêBranco
\end{tabular}

Fonte: Elaborado pelas autoras. 
Figura 3 - Poço artesiano da Associação Mata Cavalo de Baixo, que disponibiliza água para comunidade

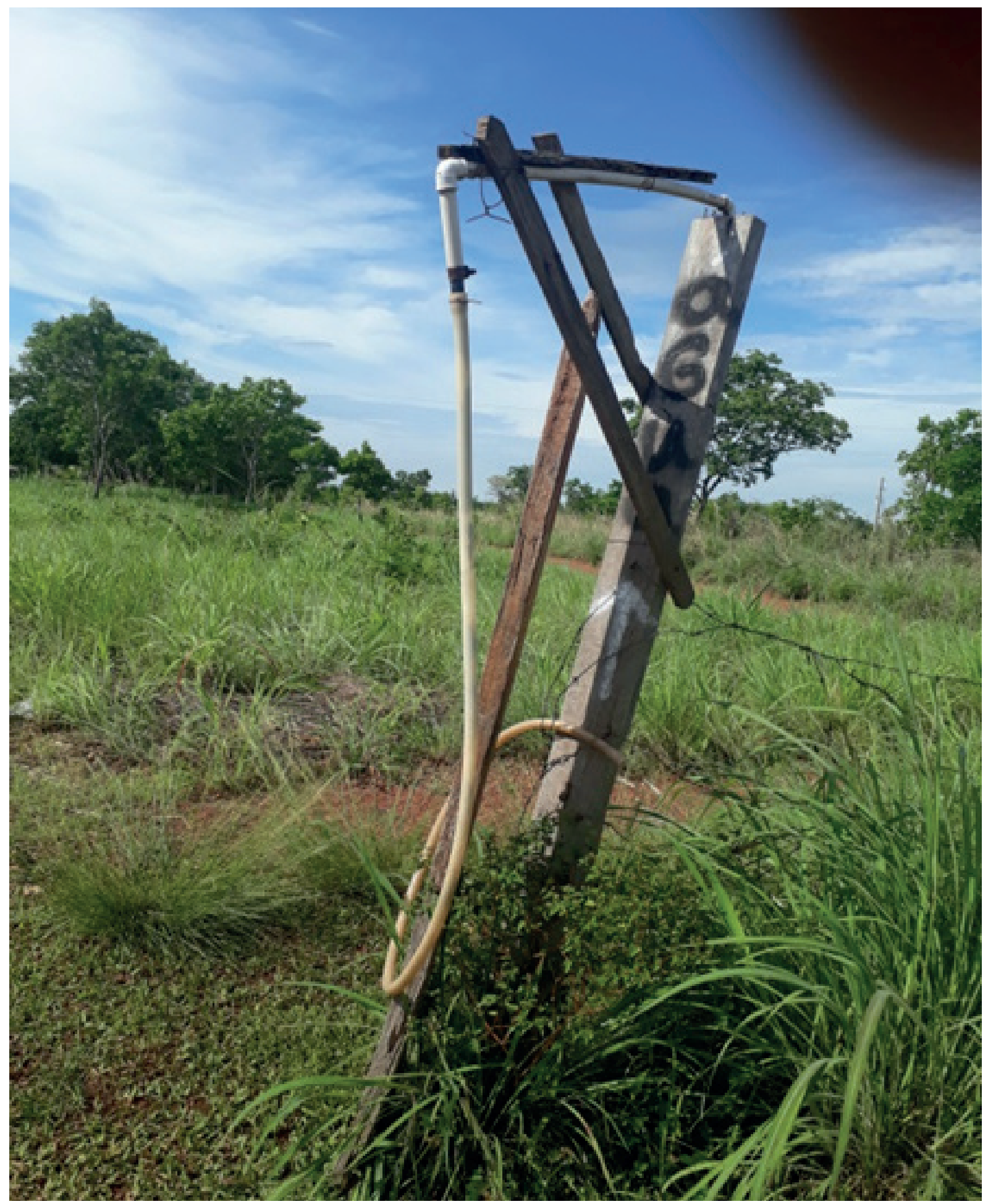

Fonte: Júnia Santana, jun. 2018. 
Em diálogo com uma das quilombolas, ela relatou que aquelas que sempre estiveram no território tratam a terra como "mãe natureza". Entretanto, aquelas que vêm com a influência da cidade acabam tendo outra concepção de preservação. É necessário, diante deste processo, trazer uma das percepções sobre Educação Ambiental, apontada por Santos e Sato (2001, p. 275):

\begin{abstract}
A percepção sobre a educação ambiental carrega valores subjetivos muito fortes, pois se insere em processos históricos e contextos diferenciados que se somam, oferecendo uma visão multicolorida. A educação ambiental ancora-se em uma visão crítica, política e reflexiva que pondere sobre a força educacional e que possa potencializar o (des)envolvimento humano intrinsecamente relacionado com a dimensão ambiental. Entretanto, mais do que isso, é uma sinergia que transcende a técnica, sendo também capaz de incluir emoção.
\end{abstract}

Este cuidado, sobre o qual as mulheres entrevistadas relataram, também vem carregado de certa preocupação, pois, nos últimos tempos, a comunidade vem sendo assolada, de forma bem acentuada, pelos impactos da garimpagem e das pastagens.

A luta contra o latifúndio é desleal e desigual, visto que ainda hoje a posse e o poder encontram-se nas mãos dos mais ricos e poderosos. Outra questão que causa maior indignação, segundo as entrevistadas, é a falta de fiscalização que favorece a elite dos fazendeiros, por meio da impunidade. Diante disso, as consequências são drásticas: nascentes de rios que morrem, diminuindo os peixes e outras espécies de animais; árvores que outrora existiam, hoje não existem mais; sem falar da escassez da água, aumentando a situação de vulnerabilidade.

Consideramos que a Educação Ambiental é um processo de aprendizagem permanente, baseado no respeito a todas as formas de vida e que este cuidado com o ambiente, mencionado por algumas destas mulheres guerreiras, causa preocupação. A falta de cuidado causa preocupação pelo fato de as mesmas saberem que no território quilombola, as pastagens e o processo da garimpagem vêm trazendo prejuízos irreparáveis para a comunidade. Os fazendeiros desmatam e destroem sem pudor algum, segundo estas guerreiras - e se não houver esta sensibilização forte e intensa, os filhos, netos, bisnetos e as gerações futuras nada poderão vislumbrar destas belezas naturais, as quais já estão comprometidas.

Precisamos de uma educação que reforce valores e ações que contribuam para a transformação humana e social e para a conservação ecológica, estimulando a formação de sociedades socialmente justas e com cuidados ecológicos que conservam entre si relações de interdependências e diversidade (SATO, 2003). Assim, a Educação Ambiental deve gerar, com urgência, mudanças na vida e maior consciência de conduta pessoal e coletiva, assim como entre os seres humanos e destes com outras formas de vida (SATO, 2003). Precisamos ter nosso direito reconhecido, precisamos ter a titulação de nosso território, para que possamos cuidar deste ambiente que para nós é tão importante.

Observando a realidade do bioma cerrado, local onde as entrevistadas estão inseridas, a preocupação com a questão ambiental e a degradação ambiental ocasionada pelo 
uso e apropriação dos elementos naturais de modo desenfreado, mostra a necessidade de a pauta ambiental estar presente nos espaços da comunidade. O bioma Cerrado apresenta níveis elevados de degradação oriundos das atividades humanas e das atividades produtivas. Manchetes com informações sobre desmatamentos e queimadas são recorrentes neste bioma e representam impactos significativos no modo de vida tradicional. Sendo assim o cuidado ambiental apresentado pelas mulheres quilombolas referencia perspectivas de continuidade de vida e produção alicerçadas na sustentabilidade ambiental.

\section{5 - CONSIDERAÇÕES FINAIS}

"Sonhar mais um sonho possível", lutar e resistir se faz necessário e, ancorada neste sonho, ousei concretizar esta pesquisa, partindo do objetivo que foi buscar conhecer as narrativas de aprendizagens de algumas mulheres que estão comprometidas com as lutas pelas terras quilombolas. Assim como ouvir sobre os obstáculos existentes, as táticas de resistência e de como estas lutas incluem o cuidado ambiental, e por serem mulheres, como aprenderam a conciliar a maternidade com as travessias cotidianas.

A oportunidade de realizar uma pesquisa com o meu povo quilombola não foi uma tarefa fácil. Por ser parte deste povo, o que justifica a pesquisa participante, tive que me portar como pesquisadora, seguindo um rigor científico, buscando não interferir nas respostas das entrevistadas. Algumas delas eram minhas alunas, tias e pessoas de convívio diário. E por ser de uma das comunidades, tive que me isentar e não me impor frente aos conflitos narrados entre os grupos.

Neste cenário de luta das quilombolas, tive a imensa satisfação de estar com elas de maneira mais próxima, compartilhando momentos e troca de saberes, com muita reciprocidade, em que percorri as seis comunidades: Aguaçu, Mata Cavalo de Baixo, Mata Cavalo de Cima, Mutuca, Ponte da Estiva e Capim Verde, dialogando com as representantes das Associações e também com aquelas que estiveram à frente dos enfrentamentos aqui narrados.

A todo momento tive como parceiras as mulheres matacavalenses, mesmo aquelas que não fizeram parte das entrevistas contribuíram direta e indiretamente no trabalho, do mesmo modo os alunos e alunas, as professoras e professores e a gestão da escola a que pertenço.

Neste contexto, estas trocas de experiências entre saberes populares e saberes formais foram tratados com muito respeito. Ainda neste diálogo foi mencionado como a maioria delas era acometida ao processo do racismo, em que os latifundiários maltratam as terras do quilombo com o garimpo e as pastagens, contribuindo para a devastação ambiental e aumentando a situação de vulnerabilidade no território.

Dar visibilidade à luta das mulheres guerreiras de Mata Cavalo é denunciar este atual desgoverno, que visa tratar de maneira desrespeitosa estas comunidades que contribuíram tanto para a formação territorial do nosso país e que hoje estão sendo ainda mais ameaçadas na sua integridade, e principalmente nos seus direitos.

Há muito ainda por fazer. Esta pesquisa é um pequeno passo. Mas, para mim, muito 
significativo, pelo tanto que aprendi em todo este processo. Há muito por resistir! Mas estas mulheres com seu cotidiano de lutas, seja no aspecto individual, da casa, da vida, da maternidade, seja no âmbito coletivo, das Associações, dos enfrentamentos, dos movimentos dentro e fora da comunidade, têm muito a nos inspirar nas lutas e resistências.

Com suas ações, elas reforçam este cuidado ambiental, ressignificando a relação atual do ser humano com a natureza, mostrando que a natureza não deve ter este sentido utilitarista que lhe é empregada, mas, antes disso, deve ser respeitada e cuidada, no próprio sentido do maternar, da mãe Terra, que provê a vida em sua essência. Estas guerreiras, em suas lutas pelos diversos direitos, e principalmente pelo direito ao território, embora suas vidas e maternidades, além do cuidado com a casa, buscam também o cuidado com a casa comum, por ambientes mais conservados no quilombo. 


\section{6 - REFERÊNCIAS}

ACSELRAD, Henri. Novas Articulações em Prol da Justiça Ambiental. Revista Democracia Viva, n. 27, 2005. Disponível em: http://www.ibase.br/pubibase/media/dv27_artigo2 ibasenet. pdf. Acesso em: fev. 2019.

BARROS, Edir Pina de. Laudo pericial histórico-antropológico. Mato Grosso: Justiça Federal, 2007.

BRANDÃO, Carlos R. (Org.). Pesquisa Participante: o saber da partilha. Aparecida do Norte: Editora Santuário, 2007.

DEALDINA, Selma dos Santos; PINTO, Cristina da Silva. Mulheres quilombolas e o direito à terra. Mulher Negra Geledés, 2017. Disponível em: https://www.geledes.org.br/category/ questoes-de-genero/mulher-negra/page/44/. Acesso em: fev. 2019.

FREIRE, Paulo. Pedagogia da autonomia. Saberes necessários à prática educativa. 25. ed. São Paulo: Paz e Terra, 1996.

GONÇALVES, Marlene F. C.; SPAZZIANI, Maria de Lourdes. In: FERRARO Jr., Luiz Antônio (Org.). Encontros e Caminhos: Formação de Educadoras(es) Ambientais e Coletivos. Brasília: MMA; Diretora de Educação Ambiental, 2005.

LEROY, Jean-Pierre; PACHECO, Tânia. Democracia. In: FERRARO Jr., Luiz Antônio (Org.). Encontros e Caminhos: Formação de Educadora(es) Ambientais e Coletivos Educadores. Brasília: MMA; Diretoria de Educação Ambiental, 2005. p. 131-137.

MANFRINATE, Rosana; SATO, Michelè. A caminhada das mulheres quilombolas de Mata Cavalo delineando seu território por entre as trilhas da educação ambiental. Revista Eletrônica do Mestrado em Educação ambiental, v. 28, p. 15, 2012.

RIBEIRO, Iselda Corrêa. Sesmeiros. Cuiabá: EdUFMT, 1998.

SANTOS, José E.; SATO, Michèle. Universidade e Ambientalismo: encontros não são despedidas. In: SANTOS, J. E.; SATO, Michèle. A contribuição da Educação Ambiental à Esperança de Pandora. São Carlos, SP: Rima, 2001.

SATO, Michelè. A contribuição da Educação Ambiental à Esperança de Pandora. São Carlos,SP: RiMa, 2001.

SATO, Michelè. Educação Ambiental. São Carlos, SP: RiMa, 2003.

SATO, Michèle et al. Comunidade quilombola de Mata Cavalo. Cuiabá: PRINT, 2010. (Caderno pedagógico). 
SATO, Michele; PASSOS, Luiz Augusto. Biorregionalismo: identidade histórica e caminhos para a cidadania. In: LOUREIRO, Carlos Frederico Bernardo; LAYRARGUES, Philippe Pomier; CASTRO, Ronaldo Souza de (Orgs.). Educação Ambiental: repensando o espaço da cidadania. 3. ed. São Paulo: Cortez, 2003.

SATO, Michèle; SILVA, Regina; JABER, Michelle. Educação Ambiental: tessituras de esperanças. Cuiabá: Editora Sustentável; EdUFMT, 2018.

SILVA, Regina; SATO, Michèle. A territorialidade das comunidades quilombolas do Estado do Mato Grosso. Seminário Política E Planejamento 2010. Anais... Curitiba, 2010.

SIMIONE, Roberta Moraes. Território de Mata Cavalo: Identidades em movimento na Educação Ambiental. 2008. Dissertação (Mestrado) - Instituto de Educação, Universidade Federal de Mato Grosso, Cuiabá, 2008. 